\title{
Study on College English Teaching Model based on Autonomous Learning
}

\author{
Yani Zong ${ }^{1, a}$ \\ ${ }^{1}$ Xi'an International University, Xi'an, Shaanxi, 710077 \\ ${ }^{a}$ email
}

\begin{abstract}
Keywords: Information Technology Networks; Independent Study; Constructivism; Teaching English
\end{abstract}

\begin{abstract}
The rapid development of science and technology in the new century gave birth to the widespread use of the Internet multimedia, from the beginning of the 1990s, network-assisted Teaching has gradually been more and more accepted by college educators, with the standard requirements of the College English classes He suggested that college English teaching also began to appear innovative change, and gradually get rid of the traditional teacher teaching mode, network technical support, full English fun and practical, given the dominant position of students, for students to find their own characteristics autonomous learning, in order to achieve effective through teaching and learning. How to use the network environment favorable opportunity to improve the quality of teaching college English, it is placed in front of each university teachers need to broaden our thinking to actively solve the problem. Based on this, according to the Construction and Construction Significance of teaching mode through self-learning mode.
\end{abstract}

\section{Introduction}

Autonomous learning, by definition, are intended to break through teacher-led classroom teaching philosophy, learning autonomy and initiative to the students. Popularity of the Internet allows students to learn English and pluralistic manner become rich, and provide convenient conditions a lot of learning on. In this situation, the student should be put aside for teachers psychological dependence, active use of the Internet for creative learning, the real control and use of language. In the beginning of the implementation, teachers must first take the initiative to change their teaching ideas, guide students to carry out independent learning classroom, so that students can apply their knowledge for further study late pave learning and transition, to better meet the social demand for higher talent .

\section{Basis and Meaning of University English Self-Learning Teaching Mode Construction}

Affected by long-term oriented education, targeting college English teaching inevitably has some limitations. On teaching objectives, often only focus on training grammar theoretical knowledge and problem-solving ability of students' writing; in teaching methods, teacher-based teaching materials simple. Thus, the traditional teaching status of the following characteristics: book value, contempt for practice; a lot of one-sided emphasis on memorizing words and sentences training, ignoring the overall integration of applications; teachings around the tests. Some schools such as the University of the 46 universities through graduate or not and whether forced together. So that students learn to deal mostly in order to obtain a certificate of examination skills, but did not really grasp the core knowledge in communication. In order to effectively improve students' English listening and speaking ability, practical translation, dialogue and exchange proficiency in English, urgent need to change the old teaching mode, innovative learning ability of students.

Constructivism is actually built on a teaching model based on (constructivism) Web-based self-learning college English teaching mode, build doctrine is the concept of learning in the cognitive psychology based on the formation. It advocates the students are learning the subject, the teacher just starting coaching with proper guidance, knowledge transfer to their students' minds to go, this time the teacher acts as a helpful role. Students to accept the knowledge processing, 
construction, form a system, and is responsible for their own learning. Including the development of autonomous learning objectives, identify learning methods, evaluate their own learning. It emphasizes students' knowledge of active exploration, active discovery and the knowledge active construction of meaning [1], and accumulated a lot of experience in repeated attempts, summed improve. Teachers need training to develop learning strategies applied to this process on. With the flourishing of Internet technology, this new learning theory from the beginning of the 1980s, they realized the organic combination with the network, and promote the idea of teaching and teaching practice autonomous learning effective combination, more and more people understand the "award to fish than giving the fishing, "the scientific truth, have a profound impact on the college English teaching reform.

As a full account of the dominant position of students, flipping the traditional classroom teaching mode model, independent learning network under the concept of establishing distinct advantages and significance in the following areas: First, take advantage of the multimedia network can provide students with language learning surroundings. The classroom with the network together, rich and innovative teaching methods of teachers, students and multimedia research study on the creation of favorable conditions. English as a language of applied disciplines, a reference to the network, such as building sites and related common platform of communication will increase the opportunities for students to use, making the atmosphere more intense learning environment better quality [2]. Secondly, multimedia network environment to increase opportunities for cooperation and exchange of teachers and students, students and students between. In English teaching model of autonomous learning, teachers will not only find a way to teach students book knowledge, but also focus on improving students' listening and speaking ability in carrying out various aspects of reading and writing in a variety of activities. Finally, in a network environment to carry out this kind of teaching model, not only for students covered by a wide range of English-related knowledge and materials to enrich their knowledge base, to develop their own vision, and allows students personality and independence are fully respected, so that their confidence and interest in learning English improved.

\section{Network Self-Learning College English Teaching Mode Construction}

Independent study emphasizes the subjectivity of students and independence. And because language learning classes are more focused on communication and communication, so the existing network technology support, college English teaching can focus on strengthening the cooperation of students. Burst out the spark thought and discussion from the collaboration of different people.

Teachers interact with students. The independent online - learning tutorials possible. Because the traditional classroom, the number of classes and more teachers can not carry out targeted a wide range of teaching, and the network is not the same platform, because of its mobility makes access to information easily and quickly. The use of network platform to interact on the one hand, the student's question be resolved timely, on the other hand, teachers can also not timely due to restrictions of time and space, closely communicate with students through the network to obtain a student's classroom feedback, work out corresponding improvement strategies, improve their teaching level. At the same time, teachers can also be carried out through the curricular knowledge extends to extracurricular activities online, independent study to build a platform or website through the network, to enable students to amateur life has become pluralistic [3]. This teaching model students and teachers through a network linked across the traditional sense of the gap between teachers and students, and promote the harmonious development of teacher-student relationship.

Student-student interaction. Common form of cooperative interaction between life and life. For example, by building corner or online English English salon, to achieve student online learning, where through dialogue and speech contests, students' listening and speaking ability to get good exercise. Of course, you can also share and exchange summary online learning experience. People discuss, express their views and opinions through a network of independent learning platform to share learning outcomes with the students to discuss and resolve on the type of difficulties encountered in the study. In this case, students not only be able to fully experience the joy of learning English, but also improve their English proficiency at each other in the supervision and 
inspiration.

Students interact with multimedia. Multimedia network with open resistance, become more flexible based on independent learning model based on network application. It no longer be bound by the traditional four-classroom, but there is more learning space and learning styles for students to choose. Meanwhile, the mobile multimedia network shortcut to free students on. For example, students in the master on the basis of textbook knowledge, according to their level of English learning and practical needs of different types of learning materials to supplement learning, choose heavy and difficult to learn, according to the learning objectives set learning progress and the development of learning plan. Network platform also provides students with a ready answer, it is possible to suspect must Solutions. Categories of university curriculum more, so little college class, and network platform for its wealth of knowledge and open information resources, so that students no longer have so much pressure and burden. Finally, multimedia courseware Ye Hao, network platform worth mentioning, intuitive distinctive features, the students' learning have to follow "naturally learn even more.

Formation of the concept. Including students and teachers in active learning concept effective guidance concept. To become the first students to instill the concept of the learning subjects. Only students actively participate in active learning and establish lifelong learning for their own learning is responsible for planning, independent learning model be possible to achieve. Traditional teacher taught a single form can be completely transformed. Students to combine their understanding of the development of weak and insufficient, explore their own points of interest, a targeted search for knowledge to learn, develop effective learning strategies and learning goals and optimize their own learning, expand their knowledge. Put their learning potential fully tapped, especially actively discussed mutual cooperation in carrying out activities with other students, and each other. Second, we must create awareness of teachers and effective guidance. Although independent study teachers no longer on the location of the body, but the full implementation of classroom activities and the successful completion of the guiding role of teachers can not be separated. Teachers can not simply let the students according to their own idea prevails, we must learn to respect for personality development of students, based on the target methodical guidance for students. Build a network platform for teachers more likely to make "individualized", on the one hand to provide teachers with a more comprehensive teaching materials and information, on the other hand to enrich the teaching methods of teachers and help teachers to better complete the classroom teaching and improve efficiency. Such as teachers when students plan to help students analyze the pros and cons and trade-offs that can help students in the way of self-learning right direction.

Network platform to build. Complete scientific network platform is the basis for self-learning students, the first school to have excellent technical support, and create a set of educational fairly standard self-learning mechanism based on the syllabus and student learning. For example, you can develop courseware library, test database, database, create a learning site for the introduction of audio-visual learning video, film and television projects, truly active classroom to achieve entertaining [4]. In addition, we can also follow the reality of English or English corner salon, opened the way English speaking English online window to guide and encourage students to boldly exchange gain knowledge in a variety of communication. Also should improve the student-teacher interaction platform for students to ask teachers questioned anywhere.

To improve the evaluation system. Independent evaluation of students learning through the network to measure. Both innovative traditional test mode, read and write English listening and speaking to students comprehensive ability test; can also be evaluated using multiple teaching modes, including complete online evaluations, electing elite, sharing impressions mechanism, so that students in their own Reflection summary and reference to others in improved and progress.

\section{Conclusion}

In short, the network environment in order to promote college English teaching mode autonomous learning concept development, is an innovation of teaching. Its innovation is that students become masters of learning, the overall quality of the culture. However, the current status of the 
implementation of the teaching point of view, there are still many areas for further improvement. This requires the majority of teachers and students to make unremitting efforts.

\section{References}

[1] Yan Mengnuo. full Internet Autonomous Learning of College English Teaching [J]. Chinese higher education, 2012 (23): 40-41.

[2] Wang Xiaojie, Du Shuping. Students' Roles in College English Autonomous Learning mode research [J]. Intellect, 2011 (9).

[3] Liu Jie. College English Autonomous Learning Mode Discussion New Role of Teachers [J]. China Education of Light Industry, 2013 (3): 82-83.

[4] Guo Qing. College English teaching mode and learning ability of students to discuss the investigation [J]. Technology and Innovation Management, 2011, 32 (5): 514-517. 